Arctic Eskimo:

a Record of Fifty Years' Experience and Observation among the Eskimo. By C. E. Whittaker. Pp. $260+16$ plates. (London : Seeley, Service and Co., Ltd., n.d.) 16s, net.

$\mathrm{T}$ his fifty years of experience of the Eskimo, Mr. 1 Whittaker has seen many changes. In that period much of their traditional mode of life has passed away, while in other respects, although superficially there has been little modification, conditions have altered fundamentally. To mention one instance only, though one that is most important for the future of the race, the scarcity of game has adversely affected hunting and trapping activities, and had not the Canadian Government intervened, the situation would have been parlous indeed.

It was, however, the whaling industry that played the most serious part in breaking down Eskimo culture, introducing the commodities, foods and especially drinks, and the diseases of civilization. When the whaling industry died out some thirty years ago, the condition of the Eskimo began to improve, and thanks to missions and hospitals, as well as in a lesser degree to schools, progress has been continuous.

In this volume the author is concerned with the traditional culture of the people rather than their present condition, although he glances at this incidentally. His most permanent and valuable contribution to understanding of the Eskimo and the character of their culture, lies in his personal observation and contact with individuals, of which his memories provide a store. His appreciation of their character with all its good qualities, as well as its weaknesses, is successfully conveyed to the reader.

The author deals chiefly with the inhabitants of the Mackenzie Delta and Hershel Island, and the Copper Eskimo of Coronation Gulf, who had not been visited by the white man before 1914; but his account of these peoples is made the basis of an account of the Western Eskimo in general.

\section{Grass Drying}

By S. W. Cheveley. Pp. $127+9$ plates. (London : Ivor Nicholson and Watson, Ltd., 1937.) 6s. net.

$\mathrm{T}$ HIS book fulfils a need in that it deals shortly but concisely with the whole subject of grass drying, tracing its development from the initial experiments at Cambridge to the product now turned out by the modern grass dryer. The general principles of grass drying are well set out, and some general idea of costs can be ascertained from the figures given. It is unfortunate that all figures are taken for one make of dryer only, and that no figures are given for plants suitable for the farmer whose intention primarily is to supply his own requirements.

The two chapters dealing with the management of the grass before and after cutting, and the general organization of the work, are well set out.

The feeding value of dried grass is given, as are suggested methods of feeding the material to different classes of stock. No results are quoted from actual feeding trials though many trials have been carried out. Reliable information of this nature, from properly designed and managed trials is, however, still needed, especially on the comparative value of spring and autumn dried grass. Methods of feeding and amounts to be fed will probably need revising when experimental results relating to these subjects are available.

No book dealing with a subject yet in its infancy can be expected to keep abreast of conditions for more than a short time. Even now, dryers other than those specified are being marketed, but no one contemplating the outlay on a drying plant can fail to benefit from reading this book.

J. R. M.

\section{The Production of Field Crops :}

a Textbook of Agronomy. By Prof. T. B. Hutcheson, T. K. Wolfe and Prof. M. S. Kipps. (McGraw-Hill Publications in the Agricultural and Botanical Sciences.) Second edition. Pp. xvii +445 . (New York and London: MeGraw-Hill Book Co., Inc., 1936.) $21 s$.

$\mathrm{T}$ HIS is essentially a book written to meet the requirements of an American course of agriculture, and it deals only with American crops and conditions; it makes no claim to be of direct use to students or teachers in Great Britain. The terminology will be strange to English readers, and many of the crop varieties mentioned are rarely heard of here.

Some of the sections, however, are of interest to English readers. One gives brief results of trials on the placement of fertilizers in relation to seed, though with the information available from American sources, much more might have been made of this subject. Another relates to the necessity of small quantities of the rarer elements for plant growth, but the practical application of this knowledge is not discussed. No mention is made of the use of mercurial seed dressings against 'bunt' and 'smuts' in cereals, the formaldehyde and copper carbonate treatments being recommended.

J. R. M.

The Naturalist's Calendar ("With Camera and Notebook"), 1939

Edited by Phyllis Barclay-Smith and Rudolf Zimmermann. Yp. 60. (London : M. C. Forrester, 1939.) 3s. $6 d$. net.

7 HIS handsome calendar should be welcomed by all lovers of natural history, since it forms an attractive vehicle for some excellent Nature photographs, which not only portray the beauties of plants and animals but are also an adequate and ready means of identification. Each page on the calendar represents one week; but the letterpress is purely supplementary to the pictures. The photographs are of mammals, birds, insects and plants found in Great Britain and have been chosen from among the best works of well-known naturalists.

The calendar would adorn the wall of a naturalist's study or a biological lecture room or laboratory. It would make a very acceptable gift to any one interested in the natural history of any group of plants or animals. 